\title{
Influence of Eu3+ Dopant on Physical and Optical Properties of Lithium-Borosulfophosphate Glasses
}

\author{
I. Bulus ${ }^{1,2^{*}}$, M. Isah ${ }^{1,3}$, M. E. Garba ${ }^{2}$, R. Hussin ${ }^{1}$, S. A. Dalhatu ${ }^{1,4}$ \\ ${ }^{1}$ Department of Physics, Faculty of Science, Universiti Teknologi Malaysia, 81310 Skudai, Malaysia. \\ ${ }^{2}$ Department of Physics, Kaduna State College of Education Gidan waya, Kafanchan, Nigeria. \\ ${ }^{3}$ Department of Physics, Kaduna State University, Nigeria. \\ ${ }^{4}$ Department of Physics, Bauchi State University, Nigeria.
}

\begin{abstract}
Multi-components glass host with enhanced physical and optical features are greatly demanding for various photonics and optoelectronics devices. Selection of suitable glass former, modifier, and dopant ions with optimized composition is a key concern in the fabrication of novel optical glass materials for the aforementioned purpose. Thus, this work reports the convectional melt quench synthesis of europium $\left(\mathrm{Eu}^{3+}\right)$ doped lithiumborosufophosphate glasses with composition $15 \mathrm{Li}_{2} \mathrm{O}-30 \mathrm{~B}_{2} \mathrm{O}_{3}-15 \mathrm{SO}_{3}-(40-x) \mathrm{P}_{2} \mathrm{O}_{5}-x \mathrm{Eu}_{2} \mathrm{O}_{3}$ (where $x=0.1,0.3,0.5$, 0.7 and 1.0 in mol\%). The effect of $\mathrm{P}_{2} \mathrm{O}_{5}$ substitution by $\mathrm{Eu}_{2} \mathrm{O}_{3}$ on their physical (density, molar volume, ion concentration, polaron radius, inter-nuclear distance and field strength) and optical properties was examined. The amorphous nature of the samples was confirmed by XRD diffraction pattern. The density of glass samples was slightly increased with increasing concentration of $\mathrm{Eu}_{2} \mathrm{O}_{3}$. Such trend is attributed to the higher molecular weight of $\mathrm{Eu}_{2} \mathrm{O}_{3}(351.926 \mathrm{~g} / \mathrm{mol})$ than $\mathrm{P}_{2} \mathrm{O}_{5}(141.9445 \mathrm{~g} / \mathrm{mol})$. The room temperature absorption spectra revealed four weak bands in the UV-Vis range and two strong bands in the NIR range with $1.0 \mathrm{~mol} \%$ glass sample possessing the highest intensity at ${ }^{7} \mathrm{~F}_{0} \rightarrow{ }^{7} \mathrm{~F}_{6}(2095 \mathrm{~nm})$. Incorporation of $\mathrm{Eu}^{3+}$ ion significantly enhanced the glass absorbance and the physical properties. The results on high refractive index $(\sim 2.3)$, polarizability and non-linear physical features suggest that these glasses are potential for photonics and solid-state laser applications.
\end{abstract}

KEYWORDS: Borosulfophosphate glasses, Europium ions, physical properties, optical properties and photoluminescence.

\section{INTRODUCTION}

The increasing demand for new, inexpensive and highly efficient optical glass host for optical device applications such as solid-state lasers, optical amplifiers, light emitting devices, display devices, sensors among others have capture the attention of many researchers in the search of novel glass host with simple synthesis procedure, excellent homogeneity and wide flexibility of chemical composition that can be customize to meet the aforesaid need.

The research interest on phosphate (P2O5) as the main network former in this study is due to its low melting points, high thermal expansion coefficient, low glass transition temperatures and softening temperature, and hence can be used as sealing having a high thermal expansion coefficient (Qian et al., 2013). However, these glasses have a relatively poor chemical durability that often limits their usability. Several authors attest that the chemical durability of phosphate glasses can be improve by addition of various oxides either network former, modifier or intermediate (Wong et al., 2014, Marimuthu, 2016).

The inclusion of borate which is another good glass former into phosphate glass network has been reported to increase the chemical durability of the phosphate glasses by contributing boron atoms into the system (Vijayakumar et al., 2015, Tonchev et al., 2015). This unified glass system called borophosphate glass matrix derived from the amalgamation

*Corresponding author's e-mail address: ibshekwolo@yahoo.com of borate and phosphate exhibit enhanced and tailored physical and optical properties compare to the pure borate and phosphate glass system (Maheshvaran and Marimuthu, 2012, Gomes et al., 2017). In addition, the drawbacks such as high phonon energy and hydroscopic nature of borophosphate host matrix can be overcome by introducing modifier reagent into the host network to improve the intensity, disrupt the lattice, open the network structure, weakened the bond strength, and lowered the viscosity of host matrix (Pang et al., 2014). In this work, lithium is added as modifier to decrease the phonon energy, hygroscopic properties and improve the strength of the host (Wong et al., 2014).

In recent time, few researchers introduced sulfate as intermediate into borophosphate forming "Borosulfophosphate glasses" to further enhance the strength of the host matrix (Kumar et al., 2012a, Kumar et al., 2012b, Ravi Kumar, 2013). These materials revealed superior features than borophosphate glasses such as low strain birefringence, low melting point, low optical loss, low nonlinear refractive index coefficient and superior refractory nature (Selvi et al., 2015). Despite the applied interest on these glass hosts, the information on physical and optical properties of borosulfophosphate glasses activated with rare earth ions is not fully understood.

In general, any glass hosts doped with rare earth ions has been a key to the development of several optical devices such 
as visible and infrared solid-state lasers, Light-emitting diodes (LEDs), optical amplifiers, sensors to mention but a few owning to their unique features such as high refraction with relatively low dispersion, high visible emission efficiency, inhomogeneous line width, stable oxidation state and several excited states for optical pumping (Janek et al., 2016). These unparallel features and the prominent applications of rare earth doped glass materials piloted our research interest in the study of their physical and optical characteristics.

Among different rare earth ions, trivalent europium (Eu3+) ion has been identified as the best dopant for inorganic lattice as well as pure red light-emitting center for display devices due to its dominant $5 \mathrm{D} 0 \rightarrow 7 \mathrm{~F} 2$ electronic transition (Keshavamurthy and Eraiah, 2015a). The selection of Eu3+ ion has proved to deserve for the study of disordered materials, because of its relatively simple energy level structure (Venkateswarlu and Rudramadevi, 2015, Boonin et al., 2016). The good correlation in physical and optical properties of Eu3+-doped glasses dictates the number of readily available new glass materials for various optical applications (Swapna, 2015, Kaewkhao et al., 2015). Due to technological importance of Europium $(\mathrm{Eu} 3+)$ ion and the advantages of above research, this study examines the influence of different concentration of Eu3+ ions on the physical and optical properties of lithiumborosulfophosphate glasses prepared by melt quenching method.

\section{MATERIALS AND METHODS}

\section{A. Sample Preparation}

Lithium- borosulfophosphate glasses doped with varying concentration of europium ions $(\mathrm{Eu} 3+)$ defined by the chemical composition 15Li2O-30B2O3-15SO3-(40-x)P2O5$\mathrm{xEu} 2 \mathrm{O} 3$ (where $\mathrm{x}=0.1,0.3,0.5,0.7$ and 1.0 in $\mathrm{mol} \%$ ) were prepared using convectional melt quenching procedure. The starting raw materials lithium carbonate (Li2CO3), boric acid (H3BO3), sulphuric acid (H2SO4) and phosphoric acid (H3PO4) and europium oxide (Eu2O3) of high purity $(99.9 \%)$ in batches (20g) were measured via precision weighing balance and mixed thoroughly in a porcelain crucible, and then placed in an electrical furnace following the procedure reported in literature (Kumar et al., 2012a).

The chemical compositions of the samples are summarized in Table 1.

Table 1: Nominal composition of Li2O-B2O3-SO3-P2O5 glasses doped with different concentration of $\mathrm{Eu} 2 \mathrm{O3}$ (in mol \%).

\begin{tabular}{ccccccc}
\hline S/no & Sample code & $\mathbf{L i}_{\mathbf{2}} \mathbf{O}$ & $\mathbf{B}_{\mathbf{2}} \mathbf{O}_{\mathbf{3}}$ & $\mathbf{S O}_{\mathbf{3}}$ & $\mathbf{P}_{\mathbf{2}} \mathbf{O}_{\mathbf{5}}$ & $\mathbf{E u}_{\mathbf{2}} \mathbf{O}_{\mathbf{3}}$ \\
\hline 1 & $0.1 \mathrm{Eu}$ & 15 & 30 & 15 & 39.9 & 0.1 \\
2 & $0.3 \mathrm{Eu}$ & 15 & 30 & 15 & 39.7 & 0.3 \\
3 & $0.5 \mathrm{Eu}$ & 15 & 30 & 15 & 39.5 & 0.5 \\
4 & $0.7 \mathrm{Eu}$ & 15 & 30 & 15 & 39.3 & 0.7 \\
5 & $1.0 \mathrm{Eu}$ & 15 & 30 & 15 & 39.0 & 1.0 \\
\hline
\end{tabular}

\section{B. Glass Sample Characterizations}

X-ray diffractograms of the samples were recorded at room temperature via Siemens X-Ray Diffractometer D5000 with Cuk $\alpha$ ( $\lambda=1.54 \AA)$ having the power source of $40 \mathrm{kV}$ and $30 \mathrm{~mA}$, and $2 \theta$ was varied from $10^{\circ}$ to $80^{\circ}$ at scanning rate of $2^{\circ}$ per minute to ascertain the amorphous nature of the synthesized samples.

Density measurements were made by using standard Archimedes method with toluene as immersing fluid (Hua et al., 2013, Wong et al., 2014, Reddy et al., 2016). The optical absorption spectra for all Eu3+-doped samples were obtained at room temperature using Shimadzu 3101 UV-Vis-NIR spectrophotometer in the range of $200-2400 \mathrm{~nm}$.

\section{Fundamental Formulae for Physical and Optical Parameters}

The basic knowledge on physical and optical parameters of newly synthesized glass material foretells its prominent physical and optical response prospective for various optical applications. In this context, the essential physical and optical parameters employed in this research are given in Tables 2 and 3 respectively.

Table 2: Physical parameters of $15 \mathrm{Li}_{2} \mathrm{O}-30 \mathrm{~B}_{2} \mathrm{O}_{3}-15 \mathrm{SO}_{3}-(40-\mathrm{x}) \mathrm{P}_{2} \mathrm{O}_{5}$ glasses activated with varying concentration of $\mathrm{Eu}_{2} \mathrm{O}_{3}$ ions.

\begin{tabular}{|c|c|c|c|}
\hline Eq. No & Parameter & Formula & Description \\
\hline 1) & $\begin{array}{l}\text { Physical parameters } \\
\text { Density }(\rho)\end{array}$ & $\rho=\frac{a}{a-b} \times \rho_{t}$ & $\begin{array}{l}a \rightarrow \text { weight of glass sample in air } \\
b \rightarrow \text { weight of sample in toluene }\end{array}$ \\
\hline 2) & Molar volume $\left(V_{m}\right)$ & $V_{m}=\frac{M}{\rho}$ & $M \rightarrow$ molecular weight of the glass sample \\
\hline 3) & Ion Concentration $\left(N_{i}\right)$ & $N_{i}=\frac{x \rho N}{M_{a}}$ & $\begin{array}{l}x \rightarrow \text { mole fraction of dopant } \\
N \rightarrow \text { Avogadro's number } \\
M_{a} \rightarrow \text { Average molecular weight of sample }\end{array}$ \\
\hline 4) & Polaron radius $\left(r_{p}\right)$ & $r_{p}(\AA)=\frac{1}{2}\left(\frac{\pi}{6 N_{i}}\right)^{1 / 3}$ & $N_{i \rightarrow}$ Ion concentration \\
\hline 5) & Inter-nuclear distance $\left(r_{i}\right)$ & $r_{i}(\AA)=\left(\frac{1}{N}\right)^{1 / 3}$ & $N_{i \rightarrow}$ Ion concentration \\
\hline 6$)$ & Field strength & $\mathrm{F}=\frac{Z}{r_{p}^{2}}$ & $Z \rightarrow$ Atomic number of the dopant \\
\hline
\end{tabular}


Table 3: Optical parameters of $15 \mathrm{Li}_{2} \mathrm{O}-30 \mathrm{~B}_{2} \mathrm{O}_{3}-15 \mathrm{SO}_{3}-(40-x)$ P2O5 glasses activated with varying concentration of $\mathrm{Eu}_{2} \mathrm{O}_{3}$ ions.

\begin{tabular}{|c|c|c|c|}
\hline Eq. No & Parameter & Formula & Description \\
\hline 1) & $\begin{array}{l}\text { optical parameters } \\
\text { Tau's Relation }\end{array}$ & $(\alpha h v)^{\frac{1}{r}}=\mathrm{A}\left(h v-E_{g}\right)$ & $\begin{array}{l}\alpha \rightarrow \text { Absorption coefficient } \\
h v \rightarrow \text { photon energy } \\
\mathrm{A} \rightarrow \text { band tailing parameter } \\
r=1 / 2 \rightarrow \text { Direct transition } \\
r=2 \rightarrow \text { Indirect transition }\end{array}$ \\
\hline 2) & Urbach Relation & $\ln \alpha=\left(\frac{h v}{\mathrm{E}_{\mathrm{Urb}}}\right)-\mathrm{c}$ & $\begin{array}{l}\mathrm{E}_{\text {Urb }}=1 / \text { slope }: \text { Urbach energy } \\
\mathrm{c} \rightarrow \text { Constant }\end{array}$ \\
\hline 3) & Refractive index $(n)$ & $\frac{n^{2}-1}{n^{2}+2}=1-\sqrt{\frac{E_{g}}{20}}$ & $E_{g} \rightarrow$ optical band gap \\
\hline 4) & Dielectric constant $(\varepsilon)$ & $\varepsilon=n^{2}$ & $n \rightarrow$ Refractive index \\
\hline 5) & Optical dielectric constant $(\epsilon)$ & $\epsilon=n^{2}-1$ & $n \rightarrow$ Refractive index \\
\hline 6) & Reflection loss (R) & $\mathrm{R}=\left(\frac{n-1}{n+1}\right)^{2}$ & $n \rightarrow$ Refractive index \\
\hline 7) & Molar refractivity $\left(R_{M}\right)$ & $R_{M}=V_{m}\left(\frac{n^{2}-1}{n^{2}+2}\right)$ & $V_{m} \rightarrow$ Molar volume \\
\hline 8) & Molar polarizability $\left(\alpha_{M}\right)$ & $\alpha_{M}=\frac{3}{4 \pi N_{i}} R_{M}$ & $N_{i} \rightarrow$ Ion Concentration \\
\hline
\end{tabular}

\section{RESULTS AND DISCUSSION}

\section{A. XRD Analysis}

The X-ray diffraction patterns of the studied glasses depicted in Figure 1 show no discrete or distinguish sharp crystalline peaks but the pattern reveal a broad hump, confirming that all our synthesized samples are fully amorphous (glassy) in nature rather than crystalline.

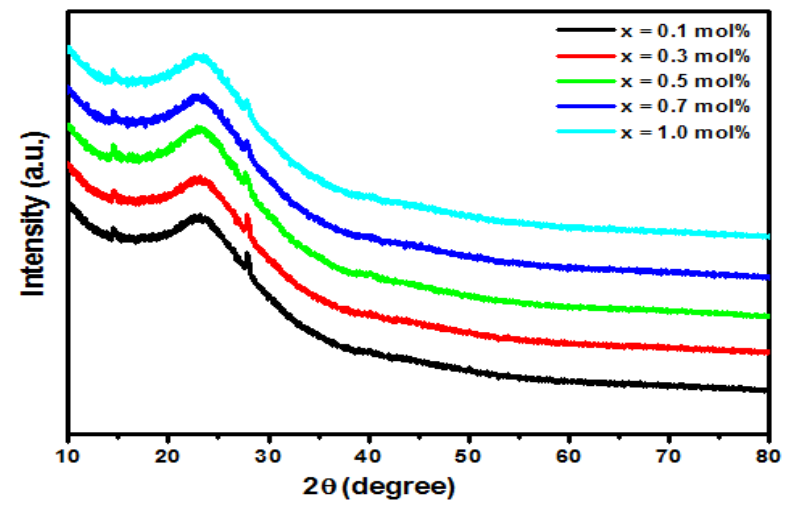

Figure 1: X-Ray Diffraction pattern of $15 \mathrm{Li}_{2} \mathrm{O}-30 \mathrm{~B}_{2} \mathrm{O}_{3}-15 \mathrm{SO}_{3}-(40-x)$ $\mathrm{P}_{2} \mathrm{O}_{5}$ glasses activated with varying concentration of $\mathrm{Eu}_{2} \mathrm{O}_{3}$ ions.

\section{B. Physical Properties Analysis}

The composition dependency on density and other vital physical parameters is significant for exploring the changes in the structure of glasses. These parameters are highly influenced by structural compactness, change in geometrical configuration, coordination number, cross-link density and dimension of interstitial spaces of the glass.

Based on the measured glass density $(\rho)$, other physical parameters such as molar volume $\left(V_{m}\right)$, Ion concentration $\left(N_{i}\right)$, Polaron radius $\left(r_{p}\right)$, inter-nuclear distance $\left(r_{i}\right)$, field strength $(\mathrm{F})$ were computed using the standard formulae described earlier in Table 1 and are presented in Table 4.

The dependences of density and molar volume of $15 \mathrm{Li}_{2} \mathrm{O}-30 \mathrm{~B}_{2} \mathrm{O}_{3}-15 \mathrm{SO}_{3}-(40-x) \mathrm{P}_{2} \mathrm{O}_{5}$

glasses on $\mathrm{Eu}^{3+}$ content shown in Figure 2 exhibit non-linear behaviour which is in agreement with other studies on $\mathrm{Eu}^{3+}$ doped glasses (Razak et al., 2016, Boda et al., 2016) and (Wagh et al., 2015). The account for the increase in density at the expense of europium content is due to the successive replacement of phosphate atom having less atomic weight by the europium atom with higher atomic. In addition, the inclusion of $\mathrm{Eu}_{2} \mathrm{O}_{3}$ to host network causes some type of structural rearrangement of the atoms. Doubtlessly $\mathrm{Eu}^{3+}$ will enter the host network by breaking up the phosphate double bond and consequently lead to the formation of more bridging oxygen (BO). This explained the modifying role of $\mathrm{Eu}^{3+}$ in the glass structure by transforming $\mathrm{PO}_{3}$ to $\mathrm{PO}_{4}$. Conversely, the decrease in molar volume implies a decrease in bond length and inter-atomic distance between the atoms. Therefore, the compactness of the glass increased and more bridging oxygen (BO) are generated which in turn increase the rigidity of the glass.

Figure 3 on the other hand, demonstrates variation of polaron radius and field strength of $15 \mathrm{Li}_{2} \mathrm{O}-30 \mathrm{~B}_{2} \mathrm{O}_{3}-15 \mathrm{SO}_{3}-$ $(40-x) \mathrm{P}_{2} \mathrm{O}_{5}$ glasses on $\mathrm{Eu}^{3+}$ content. It was observed that the polaron radius decreases proportionally with increase in $\mathrm{Eu}_{2} \mathrm{O}_{3}$ content. This decrease may be due to the increase in $\mathrm{Eu}^{3+}$ ion concentrations $\left(N_{i}\right)$ which give rise to high field strength 
Table 4: Physical properties of $15 \mathrm{Li}_{2} \mathrm{O}-30 \mathrm{~B}_{2} \mathrm{O}_{3}-15 \mathrm{SO}_{3}-(40-\mathrm{x}) \mathrm{P}_{2} \mathrm{O}_{5}$ glasses doped with different concentration of $\mathrm{Eu}_{2} \mathrm{O}_{3}$ ions.

\begin{tabular}{|c|c|c|c|c|c|}
\hline Glass sample & $x=0.1$ & $x=0.3$ & $x=0.5$ & $x=0.7$ & $x=1.0$ \\
\hline \multicolumn{6}{|l|}{ Physical parameters } \\
\hline$M_{a}(\mathrm{~g})$ & 101.934 & 102.042 & 102.150 & 102.258 & 102.420 \\
\hline$\rho\left(\mathrm{gcm}^{-3}\right)$ & 1.786 & 1.996 & 2.117 & 2.119 & 2.210 \\
\hline$v_{m}\left(\mathrm{~cm}^{3} \mathrm{~mol}^{-1}\right)$ & 59.080 & 51.126 & 48.241 & 48.205 & 46.354 \\
\hline $\mathrm{Eu}^{3+} N_{i} 10^{21}$ ionscm $^{-2}$ & 1.055 & 3.534 & 6.242 & 8.730 & 12.991 \\
\hline$r_{p}(\AA) \times 10^{-8}$ & 3.965 & 2.650 & 2.193 & 1.961 & 1.717 \\
\hline$r_{i}(\AA) \times 10^{-8}$ & 9.838 & 6.576 & 4.540 & 4.464 & 4.261 \\
\hline$F \times 10^{16} \mathrm{~cm}^{-2}$ & 4.006 & 8.969 & 13.105 & 16.389 & 21.137 \\
\hline
\end{tabular}

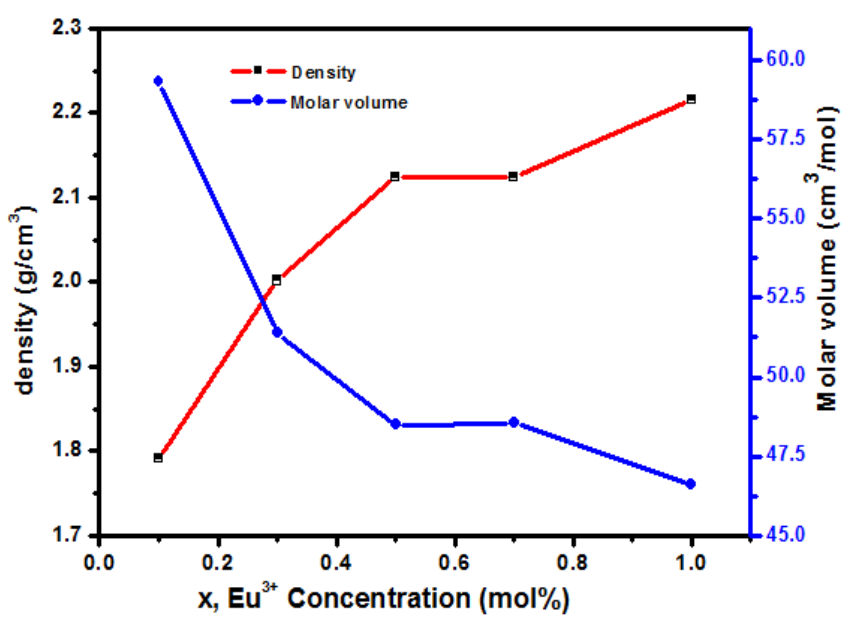

Figure 2: Density and molar volume relation of $15 \mathrm{Li}_{2} \mathrm{O}-30 \mathrm{~B}_{2} \mathrm{O}_{3}-15 \mathrm{SO}_{3}-(40-\mathrm{x}) \mathrm{P}_{2} \mathrm{O}_{5}$ glasses doped with varying concentration of $\mathrm{Eu}_{2} \mathrm{O}_{3}$ ions.

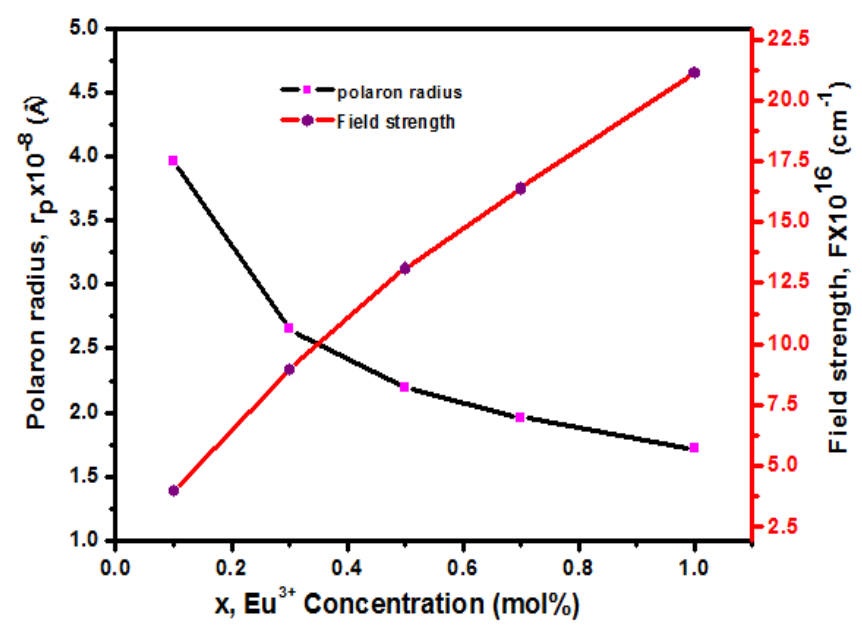

Figure 3: Variation of polaron radius and field strength of $15 \mathrm{Li}_{2} \mathrm{O}$ $3_{30 B_{2}} \mathrm{O}_{3}-15 \mathrm{SO}_{3}-(40-\mathrm{x}) \mathrm{P}_{2} \mathrm{O}_{5}$ glasses activated with varying concentration of $\mathrm{Eu}_{2} \mathrm{O}_{3}$ ions

\section{Optical Properties Analysis}

The absorption spectra of lithium-borosulfophosphate glasses activated with varying concentration of $\mathrm{Eu}^{3+}$ ions in the UV-Vis regions $(350-650 \mathrm{~nm})$ and NIR regions (2000 $2400 \mathrm{~nm}$ ) are shown in Figure 4 and 5 respectively. The observed absorption spectra in this work are in consistent with other report on $\mathrm{Eu}^{3+}$ doped glass system (Manasa and
Jayasankar, 2016, Boonin et al., 2016). The absence of welldefined sharp absorption edges as shown in Figure 4 further reinforce XRD studies, confirming that the current samples are fully amorphous in nature. The observed UV absorption edges (cut-off wavelengths) are red shifted in the range of $369-392 \mathrm{~nm}$ with increasing $\mathrm{Eu}^{3+}$ content. This slight shift to higher wavelength may be attributed to the lower rigidity of the glass from higher $\mathrm{Eu}^{3+}$ content.

The absorption spectra revealed total of six bands in all regions which are separated into two regions. Figure 4 exhibits four bands due to ${ }^{7} \mathrm{~F}_{0} \rightarrow{ }^{5} \mathrm{~L}_{6}(391 \mathrm{~nm}),{ }^{7} \mathrm{~F}_{0} \rightarrow{ }^{5} \mathrm{D}_{2}(463$ $\mathrm{nm}),{ }^{7} \mathrm{~F}_{0} \rightarrow{ }^{5} \mathrm{D}_{1}(541 \mathrm{~nm})$ and ${ }^{7} \mathrm{~F}_{0} \rightarrow{ }^{5} \mathrm{D}_{0}(580 \mathrm{~nm})$ in the UV-Vis regions whereas NIR regions (Figure 5) shows two intense bands due to ${ }^{7} \mathrm{~F}_{0} \rightarrow{ }^{7} \mathrm{~F}_{6}(2095 \mathrm{~nm})$ and ${ }^{7} \mathrm{~F}_{1} \rightarrow{ }^{7} \mathrm{~F}_{6}(2207 \mathrm{~nm})$ transitions. It is observed that $1.0 \mathrm{~mol} \%$ of $\mathrm{Eu}^{3+}$ content at ${ }^{7} \mathrm{~F}_{0} \rightarrow{ }^{7} \mathrm{~F}_{6}(2095 \mathrm{~nm})$ is found to be more intense than all other transitions. Therefore, $1.0 \mathrm{~mol} \%$ of $\mathrm{Eu}^{3+}$ doped lithiumborosulfophosphate glass may be used as potential optical glass host for optical device applications.

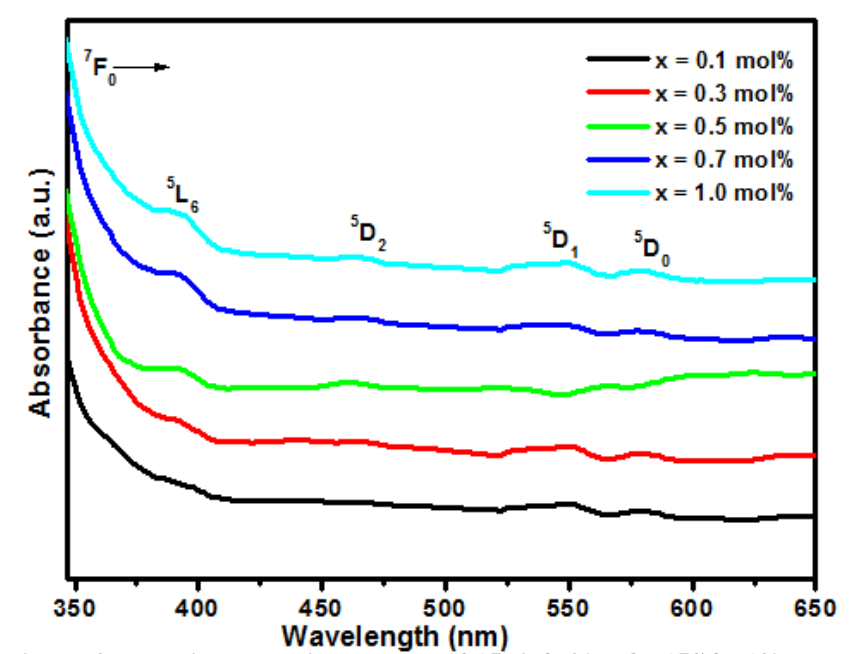

Figure 4: UV-Vis absorption spectra of $15 \mathrm{Li}_{2} \mathrm{O}-30 \mathrm{~B}_{2} \mathrm{O}_{3}-15 \mathrm{SO}_{3}-(40-$ $\mathrm{x}) \mathrm{P}_{2} \mathrm{O}_{5}-\mathrm{xEu}_{2} \mathrm{O}_{3}$ glasses 


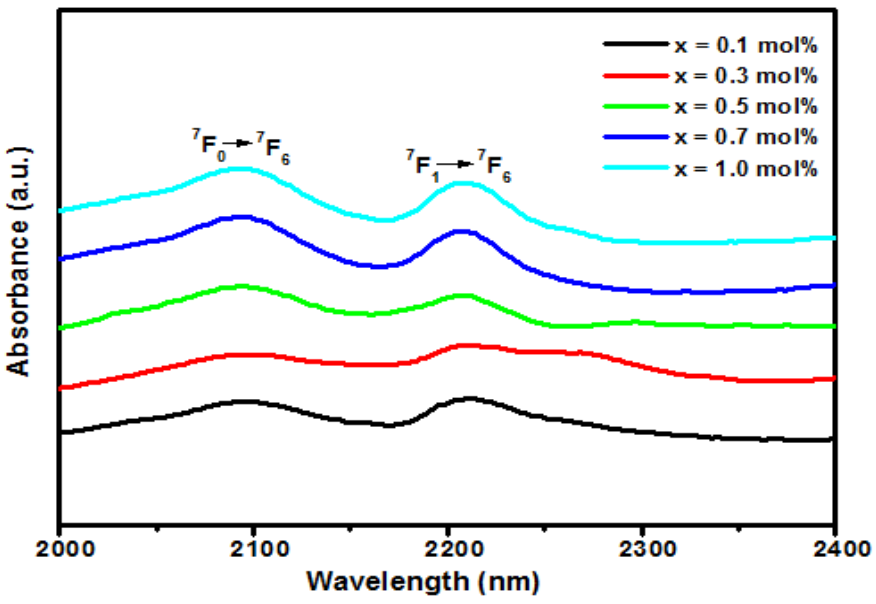

Figure 5: NIR absorption spectra of $15 \mathrm{Li}_{2} \mathrm{O}-30 \mathrm{~B}_{2} \mathrm{O}_{3}-15 \mathrm{SO}_{3}-(40-\mathrm{x}) \mathrm{P}_{2} \mathrm{O}_{5^{-}}$ $\mathrm{xEu}_{2} \mathrm{O}_{3}$ glasses.

\section{Optical Band Gap Analysis}

The energy band gap is an important feature of glassy materials which determines their optical applications. From the obtained absorption spectra and Tau's relation mentioned earlier in equation (9) of Table 3 , the plots of $(\alpha h v)^{2}$ and $(\alpha h v)^{1 / 2}$ versus photon energy at $(\alpha h v)^{2}=0$ and $(\alpha h v)^{1 / 2}=0$ are presented in Figure 6 and Figure 7 respectively. The values of direct and indirect optical band gap are estimated by extrapolating a linear part of the

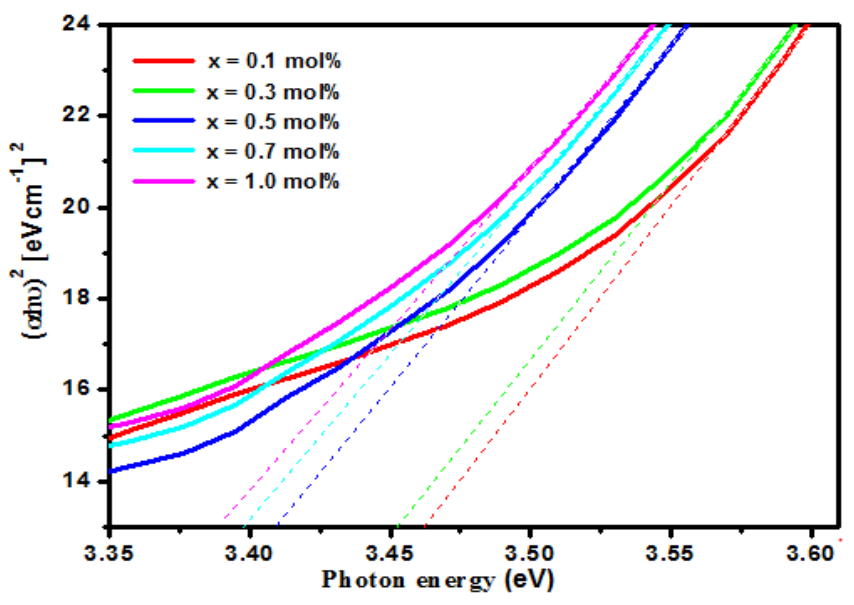

Figure 6: Direct optical energy band gap of $15 \mathrm{Li}_{2} \mathrm{O}_{-30 B_{2}}$ $\mathrm{O}_{3}-15 \mathrm{SO}_{3}-(40-x) \mathrm{P}_{2} \mathrm{O}_{5^{-}} x \mathrm{Eu}_{2} \mathrm{O}_{3}$ glasses.

aforesaid Figures to $x$-axis. The meeting points of the straight line on $\mathrm{x}$ - axis (photon energy) indicate the respective values of energy band gap and are tabulated in Table 5. As noticed from Table 5, the values of both direct and indirect optical band gap decrease as the concentration of $\mathrm{Eu}^{3+}$ increases from 0.1 to $1.0 \mathrm{~mol} \%$. This decrease in optical band gap arises from the red-shift in absorption edge resulting to the decrease in non-bridging oxygen (NBO) and hence making the glass structure more compact.

Table 5: Optical properties of $15 \mathrm{Li}_{2} \mathrm{O}-30 \mathrm{~B}_{2} \mathrm{O}_{3}-15 \mathrm{SO}_{3}-(40-x) \mathrm{P}_{2} \mathrm{O}_{5}$ glass samples doped with varying concentration of $\mathrm{Eu}_{2} \mathrm{O}_{3}$ ions.

\begin{tabular}{lcrrrr}
\hline Glass sample & $\boldsymbol{x}=\mathbf{0 . 1}$ & $\boldsymbol{x}=\mathbf{0 . 3}$ & $\boldsymbol{x}=\mathbf{0 . 5}$ & $\boldsymbol{x}=\mathbf{0 . 7}$ & $\boldsymbol{x}=\mathbf{1 . 0}$ \\
\hline Optical parameters & & & & & \\
& & & & & \\
& & & & & \\
Cut-off wavelength (nm) & 369 & 377 & 384 & 388 & 392 \\
Direct optical band gap (eV) & 3.499 & 3.489 & 3.459 & 3.439 & 3.436 \\
Indirect optical band gap (eV) & 3.468 & 3.449 & 3.398 & 3.380 & 3.351 \\
Urbach's energy (eV) & 0.289 & 0.308 & 0.313 & 0.323 & 0.333 \\
refractive index $n$ & 2.275 & 2.279 & 2.283 & 2.287 & 2.290 \\
Dielectric constant & 5.176 & 5.194 & 5.212 & 5.230 & 5.244 \\
Optical dielectric constant & 4.176 & 4.194 & 4.212 & 4.230 & 4.244 \\
Reflection loss & 0.151 & 0.152 & 0.153 & 0.153 & 0.154 \\
Molar refractivity $\left(\mathrm{cm}^{-3}\right)$ & 44.381 & 29.806 & 28.174 & 28.250 & 27.157 \\
Molar polarizability10 & & & \\
& 1.363 & 1.182 & 1.117 & 1.110 & 1.077 \\
\hline
\end{tabular}




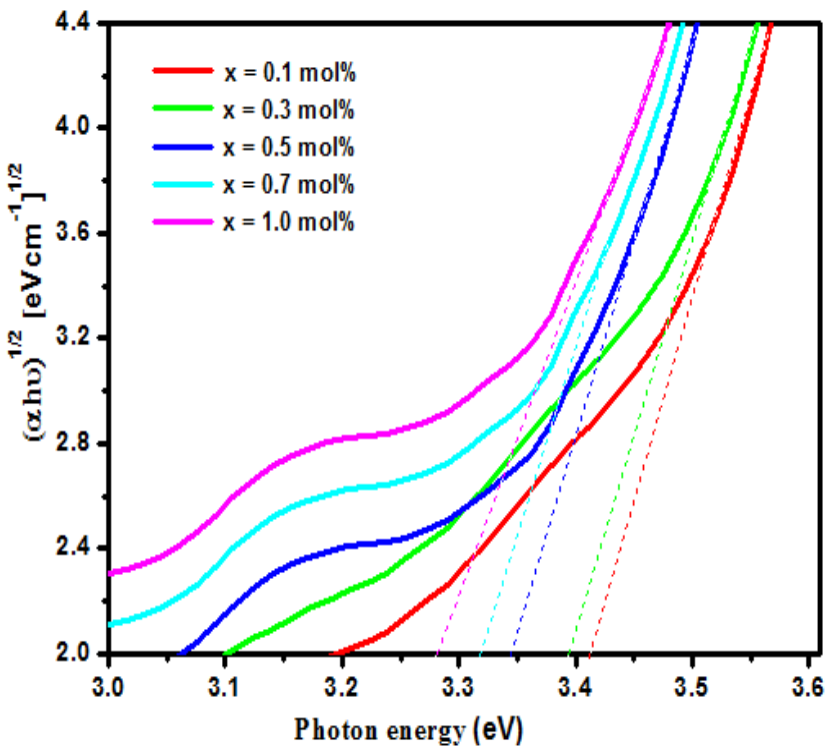

Figure 7: Indirect optical energy band gap of $15 \mathrm{Li}_{2}$ $\mathrm{O}-30 \mathrm{~B}_{2} \mathrm{O}_{3}-\mathrm{CSO}_{3}-(40-\mathrm{x}) \mathrm{P}_{2} \mathrm{O}_{5}-\mathrm{xEu}_{2} \mathrm{O}_{3}$ glasses.

\section{E. Urbach's Energy Analysis}

In this work, the logarithm of absorption coefficient $(\ln \alpha)$ was plotted as a function of $h v$. As can been seen from Figure 8, the Urbach's law is clearly verified via the linear Urbach plots of all the studied glass samples. The values of Urbach's energy given in Table 5 were evaluated by determining the slopes of the linear portion in the lower photon energy region of the curves and taking their reciprocals. The observed Urbach's energy in the range of 0.289 sto $0.333 \mathrm{eV}$ indicates the increase in structural disorder of the glasses. This results is in agreement with the value obtained for amorphous semiconductor $(0.046-0.66 \mathrm{eV})$ (Keshavamurthy and Eraiah, 2015b).

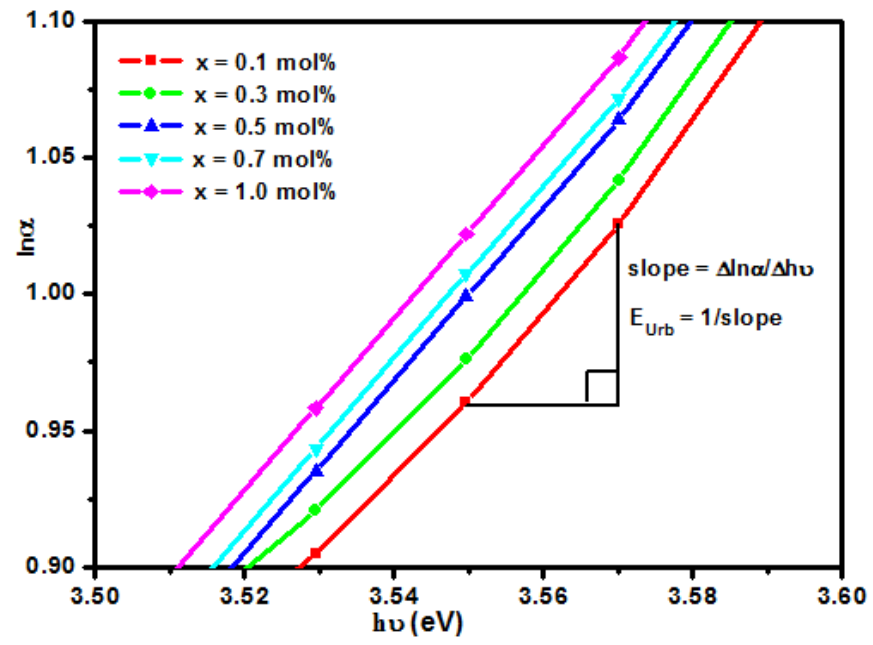

Figure 8: Urbach's energy of $15 \mathrm{Li}_{2} \mathrm{O}-30 \mathrm{~B}_{2} \mathrm{O}_{3}-15 \mathrm{SO}_{3}-(40-x)$ $\mathrm{P}_{2} \mathrm{O}_{5}-\mathrm{xEu}_{2} \mathrm{O}_{3}$ glasses.

\section{CONCLUSION}

A new class of transparent and good optical europium doped lithium- borosulfophosphate glasses were successfully synthesized by melt quenching. X-ray diffraction studies confirm the amorphous nature of the glasses. Based on the physical parameters, the increase in density and decrease in molar volume with increase in dopant concentration explained the modifying role of $\mathrm{Eu}_{2} \mathrm{O}_{3}$ in lithiumborosulfophosphate host structure. The optical absorption was slightly influenced by the variation of $\mathrm{Eu}_{2} \mathrm{O}_{3}$ concentration. Successive replacement of $\mathrm{P}_{2} \mathrm{O}_{5}$ by $\mathrm{Eu}_{2} \mathrm{O}_{3}$ leads to red shift in the fundamental absorption edge of the absorption spectra and consequently, decreases the optical band gap. $1.0 \mathrm{~mol} \%$ Eu3+ doped lithium- borosulfophosphate glass revealed prominent intensity at ${ }^{7} \mathrm{~F}_{0} \rightarrow{ }^{7} \mathrm{~F}_{6}(2095 \mathrm{~nm})$. In this view, 1.0 mol\% contained glass sample obtained from this study can be used as potential optical glass host for solid state lasers and light emitting devices.

\section{ACKNOWLEDGEMENTS}

This work was financially supported by the Universiti Teknologi Malaysia under the Research University Grant and Ministry of Higher Education Malaysia via Vote: QJ130000.2526.10H01. Ibrahim bulus, Mustapha Isah and S.A Dalhatu gratefully acknowledge the sponsorship from Kaduna state Government via overseas scholarship scheme and the Federal Government of Nigeria through academic staff training and development

\section{REFERENCES}

Boda, R.; M. Shareefuddin, M. Chary, \& R. Sayanna. (2016). FTIR and Optical Properties of Europium Doped Lithium Zinc Bismuth Borate Glasses. Materials Today: Proceedings, 3: 1914-1922.

Boonin, K.; W., Sa-Ardsin, \& J. Kaewkhao. 2016. The luminescence characteristics of $\mathrm{Eu}^{3+}$-doped lithiumgadolinium borate glasse.

Gomes, J.; A., Lima, M., Sandrini, A., Medina, A., Steimacher, F., Pedrochi, \& M., Barboza. (2017). Optical and spectroscopic study of erbium doped calcium borotellurite glasses. Optical Materials, 66: 211-219.

Hua, W. M.; Wong, P. S., Hussin, R. \& Z., Ibrahim. (2013). Structural Study on Lithium-Barium Borophosphate Glasses Using Infrared and Raman Spectroscopy. Advanced Materials Research, 2013. Trans Tech Publ: 11-15.

Janek, J.; M., Soltys, L., Żur, E., Pietrasik, J., Pisarska, \& W. A., Pisarski. (2016). Luminescence investigations of rare earth doped lead-free borate glasses modified by $\mathrm{MO}(\mathrm{M}=\mathrm{Ca}, \mathrm{Sr}, \mathrm{Ba})$. Materials Chemistry and Physics, 180: 237-243.

Kaewkhao, J.; K., Boonin, P., Yasaka, \& H., Kim. (2015). Optical and luminescence characteristics of $\mathrm{Eu}^{3+}$ doped zinc bismuth borate (ZBB) glasses for red emitting device. Materials Research Bulletin, 71: 37-41.

Keshavamurthy, K. \& Eraiah, B. (2015a). Europiumdoped boro-bismuth-tellurite glasses for multicolor phosphor applications. Canadian Journal of Physics, 94: 188-191.

Keshavamurthy, K. \& Eraiah, B. (2015b). Influence of europium $\left(\mathrm{Eu}^{3+}\right)$ ions on the optical properties of silver 
lead borate glasses. Bulletin of Materials Science, 38: 13811384.

Kumar, A. R.; C. S., Rao, G. M., Krishna, V. R. Kumar \& N., Veeraiah (2012a). Structural features of $\mathrm{MoO}_{3}$ doped sodium sulpho borophosphate glasses by means of spectroscopic and dielectric dispersion studies. Journal of Molecular Structure, 1016: 39-46.

Kumar, A. R.; C. S., Rao, N. N., Rao, V. R., Kumar, I., Kityk \& N., Veeraiah (2012b). Influence of valence and coordination of manganese ions on spectral and dielectric features of $\mathrm{Na}_{2} \mathrm{SO}_{4}-\mathrm{B}_{2} \mathrm{O}_{3}-\mathrm{P}_{2} \mathrm{O}_{5}$ glasses. Journal of NonCrystalline Solids, 358: 1278-1286.

Manasa, P. \& Jayasankar, C. (2016). Luminescence and phonon side band analysis of $\mathrm{Eu}^{3+}$-doped lead fluorosilicate glasses. Optical Materials, 62: 139-145.

Maheshvaran, K. \& Marimuthu, K. (2012). Optical Band Gap Studies on $\mathrm{Dy}^{3+}$ Doped Boro-Tellurite Glasses. Emerging Trends in Science, Engineering and Technology. Springer.

Pang, X. G.; T. Y., Eeu, P. M., Leong, W., Shamsuri, W., Nurulhuda, \& R, Hussin (2014). Structural and Luminescence Study of Rare Earth and Transition Metal Ions Doped Lead Zinc Borophosphate Glasses. Advanced Materials Research. Trans Tech Publ, 280-283.

Qian, B., X.; Liang, C, Wang,. \& S. ,Yang (2013). Structure and properties of calcium iron phosphate glasses. Journal of Nuclear Materials, 443: 140-144.

Ravi Kumar, A. V.; Ch. Srinivasa Rao, T. Srikumar, Y. Gandhi, V. RaviKumar, N. Veeraiah, (2012). Dielectric and spectroscopic investigations on $\mathrm{Na}_{2} \mathrm{SO}_{4}-\mathrm{B}_{2} \mathrm{O}_{3}-\mathrm{P}_{2} \mathrm{O}_{5}$ : $\mathrm{TiO} 2 / \mathrm{MnO} / \mathrm{MoO}_{3}$ glasses mixed with low concentrations of $\mathrm{TiO}_{2}$, Journal of Alloys and Compounds, 515: 134-142.

Reddy, C. P.; V., Naresh \& K. R, Reddy. (2016). $\mathrm{Li}_{2} \mathrm{O}$ $\mathrm{LiF} \quad \mathrm{ZnF} 2 \mathrm{~B}_{2} \mathrm{O}_{3} \quad \mathrm{P}_{2} \mathrm{O}_{5}$ : $\mathrm{MnO}$ glasses-Thermal, structural, optical and luminescence characteristics. Optical Materials, 51: 154-161.
Razak, N., S.; Hashim, M., Mhareb, Y., Alajerami, S., Azizan, \& N., Tamchek (2016). Impact of $\mathrm{Eu}^{3+}$ Ions on Physical and Optical Properties of $\mathrm{Li}_{2} \mathrm{O}-\mathrm{Na}_{2} \mathrm{O}-\mathrm{B}_{2} \mathrm{O}_{3}$ Glass. Chinese Journal of Chemical Physics, 29: 395-400.

Selvi, S.; K., Marimuthu, \& G. ,Muralidharan (2015). Structural and luminescence behavior of $\mathrm{Sm}^{3+}$ ions doped lead boro-telluro-phosphate glasses. Journal of Luminescence, 159: 207-218.

Swapna, K. (2015). Absorption and emission characteristics of $\mathrm{Dy}^{3+}, \mathrm{Sm}^{3+}, \mathrm{Eu}^{3+}, \mathrm{Tb}^{3+}$ and $\mathrm{Er}^{3+}$ ions doped zinc alumino bismuth borate glasses, $\mathrm{PhD}$ Thesis, Koneru Lakshmaiah Education Foundation, available online: http://hdl.handle.net/10603/47011

Tonchev, D.; I., Kostova, G., Okada, T., Pashova, G., Belev, G., Patronov, T., Eftimov, T., Wysokinski, D., Chapman, \& S., Kasap (2015). Samarium Doped Borophosphate Glasses and Glass-Ceramics for X-ray Radiation Sensing. Nanoscience Advances in CBRN Agents Detection, Information and Energy Security. Springer.

Vijayakumar, M. and Marimuthu, K. (2016). Tailoring the luminescence of $\mathrm{Eu}^{3+}$ co-doped $\mathrm{Dy}^{3+}$ incorporated Aluminofluoro-borophosphate glasses for White light applications. Journal of Luminescence, 178(C): 414424.

Vijayakumar, R.; G., Venkataiah, \& K., Marimuthu, (2015). Structural and luminescence studies on $\mathrm{Dy}^{3+}$ doped boro-phosphate glasses for white LED's and laser applications. Journal of Alloys and Compounds, 652: 234243.

Wagh, A.; Y., Raviprakash, V Upadhyaya,. \& S. D., Kamath (2015). Composition dependent structural and optical properties of $\mathrm{PbF}_{2}-\mathrm{TeO}_{2}-\mathrm{B}_{2} \mathrm{O}_{3}-\mathrm{Eu}_{2} \mathrm{O}_{3}$ glasses. Spectrochimica Acta Part A: Molecular and Biomolecular Spectroscopy, 151: 696-706.

Wong, P. S.; M. H., Wan, R., Hussin, H. O., Lintang, \& S., Endud (2014). Structural and luminescence studies of europium ions in lithium aluminium borophosphate glasses. Journal of Rare Earths, 32: 585-592. 